\title{
In vitro antifungal activities of leaf extracts of Lippia alba (Verbenaceae) against clinically important yeast species
}

\author{
Graziela Teixeira de Oliveira ${ }^{[1]}$, Jaqueline Maria Siqueira Ferreira ${ }^{[1]}$, Luiz Henrique Rosa ${ }^{[2]}$, \\ Ezequias Pessoa de Siqueira ${ }^{[3]}$, Susana Johann ${ }^{[2]}$ and Luciana Alves Rodrigues dos Santos Lima ${ }^{[1]}$
}

[1]. Campus Centro-Oeste Dona Lindu, Universidade Federal de São João Del-Rei, Divinópolis, MG. [2]. Departamento de Microbiologia, Instituto de Ciências Biológicas, Universidade Federal de Minas Gerais, Belo Horizonte, MG. [3]. Laboratório de Química de Produtos Naturais, Centro de Pesquisas René Rachou, Fundação Oswaldo Cruz, Belo Horizonte, MG.

\begin{abstract}
Introduction: There are few studies reporting the antifungal activities of Lippia alba extracts. Methods: A broth microdilution assay was used to evaluate the antifungal effects of Lippia alba extracts against seven yeast species of Candida and Cryptococcus. The butanol fraction was investigated by gas chromatography-mass spectrometry. Results: The butanol fraction showed the highest activity against Candida glabrata. The fraction also acted synergistically with itraconazole and fluconazole against C. glabrata. The dominant compounds in the butanol fraction were 2,2,5-trimethyl-3,4-hexanedione, 3,5-dimethyl-4-octanone and hexadecane. Conclusions: The butanol fraction may be a good candidate in the search for new drugs from natural products with antifungal activity.
\end{abstract}

Keywords: Lippia alba. Antifungal activity. Yeast.

Plants exhibit antifungal properties, and several compounds, such as coumarins, terpenes and flavonoids ${ }^{1}$, could be responsible for these activities. The incidence of invasive opportunistic mycoses has increased in immunosuppressed patients, including those undergoing organ transplantation or hematopoietic stem cell therapy and those suffering from cancer or acquired immunodeficiency syndrome (AIDS) ${ }^{2}$. Clinical Candida species remain the most important cause of opportunistic mycoses worldwide. The majority of invasive infections due to Candida spp. are attributed to several species, including Candida albicans, Candida glabrata, Candida parapsilosis, Candida tropicalis and Candida krusei ${ }^{2}$. Cryptococcus neoformans is the etiological agent of cryptococcosis and is responsible for up to $30 \%$ of deaths in AIDS patients ${ }^{3}$. Cryptococcus gattii causes cryptococcal infections mostly in immunocompetent individuals ${ }^{4}$. Despite some effective treatment options, such mycoses are associated with high morbidity ${ }^{2}$. To overcome this problem, identifying new compounds, especially natural products, that exert antifungal activities, is very important.

Lippia alba (Mill.) N.E. Brown (Verbenaceae) is a shrub widely distributed throughout South America and is popularly known as cidreira or false melissa. In traditional popular medicine, the tea from its leaves is largely utilized as a tranquilizer

Address to: $\mathrm{Dr}^{\mathrm{a}}$ Luciana Alves Rodrigues dos Santos Lima. Campus CentroOeste Dona Lindu/UFSJ. Rua Sebastião Gonçalves Coelho 400, Chanadour, 35501-296 Divinópolis, MG, Brasil.

Phone: 5537 3221-1393; Fax: 5537 3221-1614

e-mail: luarsantos@ufsj.edu.br

Received 18 January 2013

Accepted 12 August 2013 but is also used to treat gastrointestinal and respiratory infections ${ }^{5}$. Several studies have reported on the antimicrobial activity of the essential oil of $L$. alba, but there are few reports in the literature on the extracts from this species. In the present work, the extract and fractions obtained from the leaves of $L$. alba were evaluated in respect to their antifungal activities against seven clinically important yeast species. We also tested the synergistic interaction of the butanol fraction with commercial antifungal drugs.

Leaves of $L$. alba were collected in the City of Carmopólis de Minas, State of Minas Gerais (MG), Brazil, in March 2011. A voucher specimen (BHCB 147243) was deposited at the Instituto de Ciências Biológicas Herbarium, Universidade Federal de Minas Gerais, Belo Horizonte, MG, Brazil. The fresh leaf material (216.73g) was extracted by cold maceration in $95 \%$ ethanol (Vetec, Brazil) over a period of 10 days at room temperature. The extract was then filtered and concentrated in a rotary evaporator at $40^{\circ} \mathrm{C}$ under reduced pressure to yield the ethanol extract (Et, 5.83g). Part of this extract $(2.05 \mathrm{~g})$ was dissolved in $\mathrm{EtOH} / \mathrm{H}_{2} \mathrm{O}$ (7:3) and then partitioned successively with hexane, dichloromethane, ethyl acetate and butanol (Vetec, Brazil; $15 \mathrm{~mL}, 3$ times with each solvent), resulting in $1.13,0.15,0.08,0.26$ and $0.35 \mathrm{~g}$ of hexane (Hex), dichloromethane (DCM), ethyl acetate (Ac), butanol (But) and hydroalcoholic (HE) fractions, respectively.

Seven yeast species, Candida albicans ATCC 18804, C. glabrata ATCC 2001, C. krusei ATCC 200298, C. parapsilosis ATCC 22019, C. tropicalis ATCC 22019, Cryptococcus gattii ATCC 32608 and Cryptococcus neoformans ATCC 2467, were used in the biological assays. All the strains were stored at $-80^{\circ} \mathrm{C}$.

For screening of antifungal activities, the ethanol extract and fractions of $L$. alba (dissolved in dimethylsulfoxide) were diluted to a final concentration of $2,000 \mu \mathrm{g} / \mathrm{mL}$ for use in the antifungal assay. The yeast species were grown at $37^{\circ} \mathrm{C}$ in Sabouraud (Himedia, India) media. After 24h under these 
conditions, a yeast inoculum was prepared by diluting the cell suspensions appropriately in RPMI (Roswell Park Memorial Institute) 1640 (supplemented with $2 \%$ glucose). A total of $50 \mu 1$ of yeast inoculum was added to each well of a 96-well plate and adjusted to $1.0 \times 10^{6}$ cells $/ \mathrm{mL}$. After adding $25 \mu \mathrm{L}$ of the extract or control solution and $25 \mu \mathrm{L}$ of each medium to attain the desired concentrations, the plates were incubated at $37^{\circ} \mathrm{C}$ for $24 \mathrm{~h}$ for Candida or $48 \mathrm{~h}$ for Cryptococcus. As an indicator of microorganism growth, $10 \mu \mathrm{L}$ of 3-(4,5-dimethyl2-thiazolyl)-2,5-diphenyl-2 H-tetrazolium bromide (Sigma, USA) (dissolved in sterile water at $5 \mathrm{mg} / \mathrm{mL}$ ) was added to each well and incubated at $37^{\circ} \mathrm{C}$ for $4 \mathrm{~h}$. The results are expressed as the percent inhibition with respect to the controls without drugs $^{6}$. Amphotericin B $(2 \mu \mathrm{g} / \mathrm{mL})$ (Sigma, USA) was used as a positive control. All assays were performed in triplicate.

The minimal inhibitory concentration (MIC) was obtained from the broth microdilution tests performed in accordance with the guidelines in the Clinical and Laboratory Standards Institute (CLSI) document M27-A37. Suspensions from the cultures of the Candida and Cryptococcus species were prepared according to the CLSI document M27-A37 and the modifications suggested by Johann et al. ${ }^{1}$ to obtain a final inoculum of $2.5 \mathrm{x}$ $10^{3}$ cells $/ \mathrm{mL}$. Amphotericin B (Sigma, USA), fluconazole (Pfizer Pharmaceutical, USA) and itraconazole (Jansen Pharmaceutical, Belgium) were included as positive controls; the stock solutions of amphotericin B and itraconazole were prepared in dimethylsulfoxide, and fluconazole was prepared in water. Twofold serial dilutions were prepared exactly as outlined in CLSI document M27-A37. All assays were performed in triplicate.

Eight serial dilutions of the butanol fraction (1.9 to $250 \mu \mathrm{g} /$ $\mathrm{mL})$ and amphotericin B (0.008 to $1 \mu \mathrm{g} / \mathrm{mL})$ were prepared with the same solvents used in the MIC test. Fifty-microliter aliquots of each dilution of the butanol fraction were added to ninety-sixwell plates in a vertical orientation, and fifty microliters of each amphotericin B dilution was added in a horizontal orientation so that each well on the plate contained various concentrations of each sample (amphotericin B and butanol fraction). After the addition of $100 \mu$ l of C. glabrata inoculum (the same as the one used in the MIC test) to each well, the plate was cultured for $48 \mathrm{~h}$ at $37^{\circ} \mathrm{C}$. The fractional inhibitory concentration (FIC) of amphotericin $\mathrm{B}$ was calculated as the MIC of amphotericin B in the presence of the butanol fraction divided by the MIC of amphotericin B alone. The FIC of the butanol fraction was calculated in the same fashion. The fractional inhibitory concentration index (FICI) was calculated by adding both FICs. With this method, FICI $\leq 0.5$ indicated synergistic activities, $0.5<$ FICI $<2.0$ defined additive or indifferent effects, and FICI $>2.0$ described antagonistic effects $^{8}$. This analysis was also performed for the butanol fraction with fluconazole $(0.062$ to $8 \mu \mathrm{g} / \mathrm{mL})$ and itraconazole $(0.015$ to $2 \mu \mathrm{g} / \mathrm{mL})$. All assays were performed in triplicate.

Gas chromatography-mass spectrometry (GC-MS) of the butanol fraction was performed on a Shimadzu model QP5050A instrument equipped with a DB-5 column $(30 \mathrm{~m} \times 0.25 \mathrm{~mm}$, $0.25 \mu \mathrm{m})$. The initial temperature of the column was $80^{\circ} \mathrm{C}$ for $1 \mathrm{~min}$, which was then increased at a rate of $7^{\circ} \mathrm{C} / \mathrm{min}$ to $300^{\circ} \mathrm{C}$ and held for $5 \mathrm{~min}$; the injector temperature was kept at $250^{\circ} \mathrm{C}$ (split 1:20), and the detector temperature was kept at $260^{\circ} \mathrm{C}$. Helium $(\mathrm{He})$ was used as the carrier gas, with a linear flowrate of $39.3 \mathrm{~mL} / \mathrm{min}(115.4 \mathrm{Kpa})$. For each analysis, $1 \mu \mathrm{L}$ of the sample was injected into the GC. The scan range was from 50 to $500 \mathrm{~m} / z$ at a scan rate of $0.50 \mathrm{scan} / \mathrm{s}$. The solvent delay was $2.5 \mathrm{~min}$. The compounds were identified by a mass spectral database search (NIST) (National Institute of Standards and Technology), followed by matching of MS data and expressed as relative percentages of each compound, calculated by internal normalization of the chromatographic peak area. All volatile compounds showing mass spectra with match factors $\geq 90 \%$ were put on a positive list of tentatively identified metabolites.

The antifungal effect of the ethanol extract and fractions of $L$. alba was screened against seven yeast species of clinical interest at a concentration of $2,000 \mu \mathrm{g} / \mathrm{mL}$ (Figure 1). C. krusei was the species most sensitive to the ethanol extract

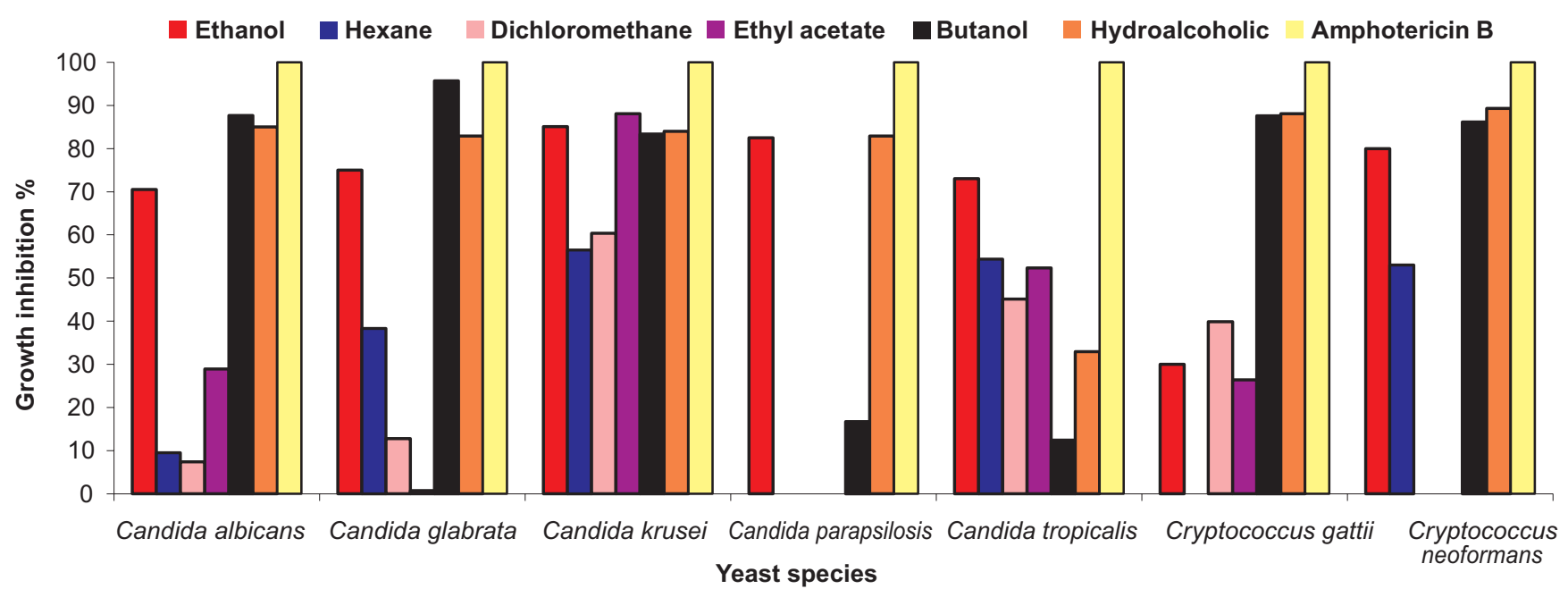

FIGURE 1 - Growth inhibition of seven yeast species of clinical interest by ethanol extract and fractions of Lippia alba at concentration of 2,000 $\mu \mathrm{g} / \mathrm{mL}$. 
and fractions, with inhibition rates ranging from $57 \%$ to $88 \%$. The ethanol extract and hydroalcoholic fraction were also active against the yeast species. The butanol fraction showed the highest growth inhibition against $C$. glabrata $(95 \%)$ compared with the other fractions and with the ethanol extract of $L$. alba.

After the screen, all fraction activities were evaluated in the MIC tests. The butanol fraction showed the highest activity against $C$. glabrata, with a MIC value of $62.5 \mu \mathrm{g} /$ $\mathrm{mL}$, and was also active against the other yeast species tested, C. albicans, C. krusei, C. gattii and C. neoformans. However, for the other species, the MIC value was $2,000 \mu \mathrm{g} / \mathrm{mL}$ (Table 1). The ethanol extract and ethyl acetate fraction showed activity against $C$. krusei, with a MIC value of $1,000 \mu \mathrm{g} / \mathrm{mL}$. The ethanol extract also presented activity against $C$. parapsilosis and C. neoformans with a MIC of $1,000 \mu \mathrm{g} / \mathrm{mL}$, and against $C$. albicans, C. glabrata and C. tropicalis, with a MIC of $2,000 \mu \mathrm{g} / \mathrm{mL}$.

The hydroalcoholic fraction was active against C. albicans, C. glabrata, C. krusei, C. parapsilosis, C. gattii and C. neoformans, with a MIC of $2,000 \mu \mathrm{g} / \mathrm{mL}$. The dichloromethane fraction displayed activity only against $C$. krusei, with a MIC of $2,000 \mu \mathrm{g} / \mathrm{mL}$. In contrast, the hexane fraction was inactive against all the yeast species studied. Notably, the ethanol extract and fractions of $L$. alba were less potent than amphotericin B, fluconazole and itraconazole.

The activity of the butanol fraction against $C$. glabrata, but not for other Candida species or Cryptococcus, could be explained because these yeast species are phylogenetically different. C. glabrata is a species more phylogenetically related to Saccharomyces cerevisiae than other pathogenic Candida species $^{9}$. The specific activity of the butanol fraction against C. glabrata also suggests a selectivity of the natural products present in this fraction.

The antifungal activities observed in the present work have been confirmed by other studies on $L$. alba extracts, being used against $C$. albicans, $C$. krusei, and $C$. tropicalis. To the best of our knowledge, this study is the first to show the antifungal activity of the ethanol extract and fractions of leaves of $L$. alba against $C$. glabrata and $C$. gattii.

The hexane and chloroform extracts from the leaves and flowers of $L$. alba showed activity against C. albicans ${ }^{10}$. The hydroalcoholic and methanol extracts obtained from the leaves of $L$. alba exerted effects against $C$. krusei, with MIC values of 125 and $165.2 \mu \mathrm{g} / \mathrm{mL}$, respectively ${ }^{11,12}$. The hydroalcoholic extract also showed activity against $C$. tropicalis, with a MIC of $1,000 \mu \mathrm{g} / \mathrm{mL}^{11}$.

The effect against Candida species is interesting, mainly because of the innate resistance of $C$. krusei to fluconazole. Candida glabrata shows less susceptibility than other Candida species, and the development of resistance to fluconazole among the clinical strains of C. albicans, C. parapsilosis and Candida tropicalis, hampers the treatment of these infections ${ }^{13}$. The activity against $C$. neoformans is of particular importance, as this yeast is the major cause of meningitis in AIDS patients and has been identified as the fourth most common cause of life-threatening infection in AIDS patients ${ }^{14}$.

To explore the possibility of developing more effective combination therapies, the butanol fraction from the leaves of L. alba was combined with amphotericin B, itraconazole and fluconazole and tested against $C$. glabrata. Table 2 shows the additive or indifferent effect of combining the butanol fraction with amphotericin B, and the synergistic effect of this fraction with itraconazole and fluconazole. These results are very interesting because C. glabrata exhibits intrinsic resistance against azole antifungal drugs ${ }^{15}$.

In this study, we showed that the butanol fraction from the leaves of $L$. alba, combined with fluconazole and itraconazole, had a synergistic effect against $C$. glabrata and, therefore, could be an alternative in the treatment of candidemia caused by this yeast species. However, additional studies are needed to evaluate the toxicity of this fraction and the in vivo action of fluconazole and itraconazole combined with the butanol fraction against this opportunistic yeast.

TABLE 1 - Minimal inhibitory concentration activity of ethanol extract and fractions of Lippia alba against seven clinically important yeast species.

\begin{tabular}{|c|c|c|c|c|c|c|c|c|c|}
\hline Fungi & \multicolumn{8}{|c|}{$\operatorname{MIC}(\mu \mathrm{g} / \mathrm{mL})$} & fluconazole \\
\hline Candida albicans & 2,000 & $\geq 2,000$ & $\geq 2,000$ & $\geq 2,000$ & 2,000 & 2,000 & 0.25 & 0.031 & 2 \\
\hline Candida glabrata & 2,000 & $\geq 2,000$ & $\geq 2,000$ & $\geq 2,000$ & 62.5 & 2,000 & 0.125 & 0.25 & 4 \\
\hline Candida krusei & 1,000 & $\geq 2,000$ & 2,000 & 1,000 & 2,000 & 2,000 & 0.5 & 0.125 & 32 \\
\hline Candida tropicalis & 2,000 & $\geq 2,000$ & $\geq 2,000$ & $\geq 2,000$ & $\geq 2,000$ & $\geq 2,000$ & 1.0 & 0.062 & 2 \\
\hline Cryptococcus gattii & $\geq 2,000$ & $\geq 2,000$ & $\geq 2,000$ & $\geq 2,000$ & 2,000 & 2,000 & 1.0 & 0.031 & nt \\
\hline Cryptococcus neoformans & 1,000 & $\geq 2,000$ & $\geq 2,000$ & $\geq 2,000$ & 2,000 & 2,000 & 1.0 & 0.031 & $\mathrm{nt}$ \\
\hline
\end{tabular}

MIC: minimal inhibitory concentration; Et: ethanol extract; Hex: hexane fraction; DCM: dichloromethane fraction; Ac: ethyl acetate fraction; But butanol fraction; HE: hydroalcoholic fraction; nt: not tested. 
TABLE 2 - FIC and FICI of the butanol fraction from Lippia alba leaves against Candida glabrata ATCC 2001.

\begin{tabular}{lcrr}
\hline Samples & MIC in combination $(\mu \mathrm{g} / \mathrm{mL})$ & MIC alone $(\mu \mathrm{g} / \mathrm{mL})$ & FIC \\
\hline 1. Butanol fraction & 0.975 & 62.5 & 0.015 \\
2. Amphotericin B & 0.125 & 0.125 & 1.015 \\
1. Butanol fraction & 0.975 & 62.5 & 0.015 \\
2. Itraconazole & 0.015 & 0.25 & 0.075 \\
1. Butanol fraction & 0.975 & 62.5 & 0.0156 \\
2. Fluconazole & 0.062 & 4 & 0.0155
\end{tabular}

FIC: fractional inhibitory concentration; FICI: fractional inhibitory concentration index; MIC: minimal inhibitory concentration.

The butanol fraction showed a higher antifungal activity than the other fractions or the ethanol extract against C. glabrata. Therefore, GC/MS was used to identify the main compounds. The dominant compounds were 2,2,5-trimethyl3,4-hexanedione, 3,5-dimethyl-4-octanone and hexadecane. There are currently no reports in the literature that describe the antifungal activity of these compounds, suggesting that the antifungal activity of plant extracts or fractions could be linked to the synergistic interactions between their components.

\section{CONFLICT OF INTEREST}

The authors declare that there is no conflict of interest.

\section{FINANCIAL SUPPORT}

Financial support and fellowships: Conselho Nacional de Desenvolvimento Cientifico e Tecnológico (CNPq), the Fundação de Amparo a Pesquisa do Estado de Minas Gerais (FAPEMIG) and the Coordenação de Aperfeiçoamento de Pessoal de Nível Superior (CAPES).

\section{REFERENCES}

1. Johann S, Cisalpino PS, Watanabe GA, Cota BB, Siqueira EP, Pizzolatti MG, et al. Antifungal activity of extracts of some plants used in the Brazilian traditional medicine against the pathogenic fungus Paracoccidioides brasiliensis. Pharmac Biol 2010; 48:388-396.

2. Nucci M, Queiroz-Telles F, Tobo AM, Restrepo A, Colombo AL. Epidemiology of opportunistic fungal infections in Latin America. Clin Infect Dis 2010; 51:561-570.

3. Idnurm A, Yong-Sun B, Nielsen K, Lin X, Fraser JA, Heitman J. Deciphering the model pathogenic fungus Cryptococcus neoformans. Nat Rev Microbiol 2005; 3:753-764.
4. Menezes RP, Penatti MPA, Pedroso RS. Different culture media containing methyldopa for melanin production by Cryptococcus species. Rev Soc Bras Med Trop 2011; 44:591-594.

5. Farias MR, Pértile R, Correa MM, Almeida MTR, Palermo JA, Schenkel EP. Triterpenoid saponins from Lippia alba (Mill.) N.E. Brown. J Braz Chem Soc 2010; 21:927-933.

6. Carvalho CR, Gonçalves VN, Pereira CB, Johann S, Galliza IV, Alves TMA, et al. The diversity, antimicrobial and anticancer activity of endophytic fungi associated with the medicinal plant Stryphnodendron adstringens (Mart.) Coville (Fabaceae) from the Brazilian savannah. Symbiosis 2012, 57:95-107.

7. Clinical and Laboratory Standards Institute (CLSI). Reference Method for Broth dilution Antifungal susceptibility testing of Yeast: Approved Standard M27-A3. Wayne (PA). USA: CLSI; 2008.

8. White RL, Burgess DS, Mandururu M, Bosso JA. Comparison of three different in vitro methods of detecting synergy: time kill, checkboard, and E-test. Antimicrob Agents Chemother 1996; 40:1914-1918.

9. Parra-Ortega B, Cruz-Torres H, Villa-Tanaca L, Hernández-Rodríguez C. Phylogeny and evolution of the aspartyl protease family from clinically relevant Candida species. Mem Inst Oswaldo Cruz 2009; 104:505-512.

10. Ara N, Nur MH, Amran MS, Wahid MII, Ahmed M. In vitro antimicrobial and cytotoxic activities of leaves and flowers extracts from Lippia alba. Pak J Biol Sci 2009; 12:87-90.

11. Holetz FB, Pessini GL, Sanches NR, Cortez DAG, Nakamura CV, Dias Filho BP. Screening of some plants used in the Brazilian folk medicine for the treatment of infectious diseases. Mem Inst Oswaldo Cruz 2002; 97:1027-1031.

12. Tempone AG, Sartorelli P, Teixeira D, Prado FO, Calixto IARL, Lorenzi H, et al. Brazilian flora extracts as source of novel antileishmanial and antifungal compounds. Mem Inst Oswaldo Cruz 2008; 103:443-449.

13. Furlaneto MC, Rota JF, Quesada RMB, Furlaneto-Maia L, Rodrigues R, Oda S, et al. Species distribution and in vitro fluconazole susceptibility of clinical Candida isolates in a Brazilian tertiary-care hospital over a 3-year period. Rev Soc Bras Med Trop 2011; 44:595-599.

14. Casolari C, Rossi T, Baggio G, Coppi A, Zandomenegui G, Ruberto AI, et al. Interaction between saquinavir and antimycotic drugs on C. albicans and C. neoformans strains. Pharmacology Research 2004; 50:605-610.

15. Kiraz N, Dag I, Oz Y, Yamac M, Kiremitci A, Kasifoglu N. Correlation between broth microdilution and disk diffusion methods for antifungal susceptibility testing of caspofungin, voriconazole, amphotericin B, itraconazole and fluconazole against Candida glabrata. J Microbiol Methods 2010; 82:136-140. 